\begin{tabular}{|c|c|c|}
\hline \multirow{3}{*}{$\begin{array}{r}\text { Case Reports in } \\
\text { Gastroenterology }\end{array}$} & \multirow{2}{*}{\multicolumn{2}{|c|}{ Case Rep Gastroenterol 2016;10:720-727 }} \\
\hline & & \\
\hline & $\begin{array}{l}\text { DOI: } 10.1159 / 000450538 \\
\text { Publisnea oninne: TNovember 25, } 2016\end{array}$ & $\begin{array}{l}\text { (c) } 2016 \text { The Author(s) } \\
\text { Published by S. Karger AG, Basel } \\
\text { www.karger.com/crg }\end{array}$ \\
\hline & \multicolumn{2}{|c|}{$\begin{array}{l}\text { This article is licensed under the Creative Commons Attribution-NonCommercial } 4.0 \\
\text { International License (CC BY-NC) (http://www.karger.com/Services/OpenAccessLicense). } \\
\text { Usage and distribution for commercial purposes requires written permission. }\end{array}$} \\
\hline
\end{tabular}

\title{
Multiple Magnetic Foreign Bodies Causing Severe Digestive Tract Injuries in a Child
}

\author{
Xinmin $\mathrm{Si}^{\mathrm{a}}$ Baofeng $\mathrm{Du}^{\mathrm{b}}$ Lei Huang ${ }^{\mathrm{b}}$ \\ ${ }^{a}$ Department of Gastroenterology, the First Affiliated Hospital of Nanjing Medical \\ University, Nanjing, China; ${ }^{\mathrm{b}}$ Department of Pediatric Surgery, Nanjing Children's Hospital \\ Affiliated to Nanjing Medical University, Nanjing, China
}

\section{Keywords}

Foreign body ingestion $\cdot$ Digestive tract injury $\cdot$ Childhood $\cdot$ Magnetic toys

\begin{abstract}
Foreign body (FB) ingestion is a common emergency as well as a major cause of accidental injury and represents a severe public health problem in childhood, especially in infants. Most cases of FB ingestion reported in children aged between 6 months and 3 years depend primarily on the fact that young children are more likely to explore objects using their mouth and are not able to distinguish edible objects from nonedible ones, their teeth are physiologically lacking, and they have poor swallowing coordination. Although, sometimes it can cause serious complications, FB ingestion generally has a low mortality rate. However, accidental ingestion of magnetic toys, as a rare kind of FB mostly encountered in children, has now become more common due to the increased availability of objects and toys with magnetic elements. The majority of magnetic FB traverse the gastrointestinal (GI) system spontaneously without complication, but in rare cases may cause severe damages to the GI tract due to its special pathogenesis [Kay and Wyllie: Curr Gastroenterol Rep 2005;7:212-218]. Ingestion of multiple magnets may be related to increased morbidity resulting in a delay of recognition of FB injury that can lead to serious complications and require surgical resolution.
\end{abstract}




\section{Case Reports in Gastroenterology}

Case Rep Gastroenterol 2016;10:720-727 DOI: $10.1159 / 000450538$

(c) 2016 The Author(s). Published by S. Karger AG, Basel www.karger.com/crg

Si et al.: Multiple Magnetic Foreign Bodies Causing Severe Digestive Tract Injuries in a Child

\section{Introduction}

Foreign body (FB) ingestion is a common emergency as well as a major cause of accidental injury and represents a severe public health problem in childhood, especially in infants [1]. Most cases of FB ingestion reported in children aged between 6 months and 3 years depend primarily on the fact that young children are more likely to explore objects using their mouth and are not able to distinguish edible objects from nonedible ones, their teeth are physiologically lacking, and they have poor swallowing coordination [2, 3]. Although, sometimes it can cause serious complications, FB ingestion generally has a low mortality rate. However, accidental ingestion of magnetic toys, as a rare kind of FB mostly encountered in children, has now become more common due to the increased availability of objects and toys with magnetic elements. The majority of magnetic FB traverse the gastrointestinal (GI) system spontaneously without complication, but in rare cases may cause severe damages to the GI tract due to its special pathogenesis [2]. Ingestion of multiple magnets may be related to increased morbidity resulting in a delay of recognition of FB injury that can lead to serious complications and require surgical resolution [4].

Here, we present a rare case of a child with severe GI injuries caused by accidental ingestion of multiple magnetic FB who was successfully treated and cured in Nanjing Children's Hospital affiliated to Nanjing Medical University in January 2016. We report this case in order to improve the clinical management of children in whom FB, especially magnetic FB, injuries occurred, reduce the risk of complications and death, and to develop strategies for prevention.

\section{Case Presentation}

A previously healthy 20-month-old male infant transferred to the surgical service of Nanjing Children's Hospital affiliated to Nanjing Medical University had been admitted for continuous emesis, unalleviated abdominal pain, and paroxysmal dysphoria. Three days before, the boy was brought to the local community hospital by his mother because of the same symptoms noted above in consideration of acute gastroenteritis, and he was given oral cephalosporin antibiotics. However, without any clinical improvement, the boy was then transferred to Nanjing Children's Hospital. No fever was experienced. Physical examination was unremarkable. The positive physical signs were observed with slightly higher muscular tone and subdued borborygmus. Then, imaging examinations were conducted. B-type ultrasonography (US) revealed right lower quadrant abdominal flatulence with partial bowel dilatation and effusion. Plain abdominal radiograph on an erect position revealed several irregular radiopacities in the pelvic cavity and dilated intestine with air-fluid levels in the upper abdomen. Subsequently, abdominal computerized tomography (CT) scan was performed. Multiple metal density shadows were detected in the pelvic cavity and ileus and diagnosed as multiple FB in the GI tract.

The patient underwent an emergency laparotomy in the afternoon. Intraoperatively, several magnetic balls were found both in and out of the tract (Fig. 1). Magnetic attraction force caused pressure bowel necrosis with perforation, effusion and fistula in jejunum and ileum (Fig. 2, Fig. 3). The intestine conglutinated together and totally 11 perforations were detected (Fig. 3). After 12 magnetic toys were removed (Fig. 4), partial intestinal resection was performed in 3 places. The procedure was successful and the perforations were repaired. After the surgery, the ankylenteron was reduced. The postoperative course was un- 
Si et al.: Multiple Magnetic Foreign Bodies Causing Severe Digestive Tract Injuries in a Child

remarkable. There was no postoperative complication, and the child was discharged 11 days later.

\section{Discussion}

With the commercial availability of small, high-powered, rare-earth magnets in toys and desktop novelties, the morbidity of magnets ingestion has a paralleled steady increase in children. Unlike other common FB, ingestion of magnetic FB can cause severe GI injuries, especially when ingested together with paramagnetic metal which even lead to death due to its special pathogenic mechanism [5]. Besides, the length of the incubation period depends on several factors, including the magnetic field intensity, the time interval of multiple magnets ingestion, and the amount of FB [6]. FB ingestion is common in pediatrics. Clinically, $80 \%$ of the FB ingestion cases usually occurred in children aged between 6 months and 3 years, which makes it very difficult to get the exact history [2]. Meanwhile, most of the children may have mild or even no clinical symptoms in the first few hours or weeks after the ingestion of magnetic FB. Then, they slowly begin to develop such symptoms as nausea, vomit, and continuous or intermittent abdominal pain (intermittent abdominal pain may even last for 6 months in some cases). The majority of these children showed no changes in the laboratory examination except for the changes of WBC and CRP in the early stage. As a result, it is difficult for most of the children to get timely diagnosis and effective treatment. Someone may even get misdiagnosed [7].

Generally, a single magnetic FB can pass through the GI tract without complication when swallowed by accident. However, 2 or more magnetic FB can attract each other in the GI tract, which causes pressure bowel necrosis with perforation, peritonitis, intestinal obstruction, and even abdominal abscess [8]. The small intestine, the longest part in the digestive tract with the most natural curve, gets the highest incidence of complications (51.3\%), followed by the small intestine-colon fistula (16.6\%), and the stomach-jejunum fistula (13.9\%) [9]. Thus, ingestion of $\mathrm{t} 2$ or more magnetic FB or magnetic FB with other paramagnetic metal may result in severe complications different from common FB ingestion and need to be specially diagnosed and treated. It is hard for multiple magnets to pass through the digestive tract and finally requires removal by laparotomy.

Intervention and treatment methods include GI endoscopy, laparoscopy, endoscopic, and laparoscopic surgery and endoscopic double laparotomy. After comprehensive analysis of this patient with a history of FB ingestion 3 days before, it is unlikely that the FB still remained in the upper digestive tract. Clinical manifestations presented as vomiting, abdominal distension, and other symptoms of intestinal obstruction. Imaging examinations showed multiple pieces of metallic FB gathered in the pelvic. The patient was admitted in nighttime emergency due to acute abdominal emergency surgery indications. Under these circumstances, elective laparoscopic GI endoscopy or gastroscopy plus dual endoscopic surgery was not appropriate, so we decisively chose emergency laparotomy.

\section{Conclusion}

FB ingestion is usually encountered in children aged between 1 and 3 years. Children at that age are curious about everything and can come into contact with various items without the ability of self-protection. They often put the small items inside their mouth including 
Si et al.: Multiple Magnetic Foreign Bodies Causing Severe Digestive Tract Injuries in a Child

magnet toys and accidently swallowed them. Since the symptoms and physical examinations are usually unremarkable, there are still many misdiagnosed cases. Clinicians should pay more attentions to patients, particularly infants, when they have symptoms like nausea, vomit, dysphoria, etc. Public education and prevention efforts are indispensable to decrease the incidence of ingestion of magnet toys. For children, prevention is the most important and basic step in magnet ingestion. The rising incidences of magnet ingestions raise awareness of the importance of changing the bad habit of putting toys into the mouth. Once the magnet ingestion is found, the patient should fast and immediately be sent to the hospital. Swallowing up the toy by force is prohibited for it may cause complications which can be avoided and makes thing more complicated. Medical history, clinical symptoms, number, location, shape, and type of magnet, and the time interval of magnets ingestion together guide the role of the pediatric gastroenterologists and surgeons in the management. Close observation and early intervention, through endoscopy or surgical exploration, may help prevent more severe complications. In conclusion, the earlier magnets ingestion is diagnosed and located the lower risk and less damage it brings.

\section{Statement of Ethics}

All procedures performed in studies involving human participants were in accordance with the ethical standards of the institutional review board. This article does not contain any studies with animals performed by any of the authors. Informed consent was obtained from all individual participants included in the study.

\section{Disclosure Statement}

The authors declare that they have no conflicts of interest.

\section{References}

1 Brown JC, Baik FM, Ou HC, Otjen JP, Parish HG, Chan DK: Upper aerodigestive magnetic foreign bodies in children. Laryngoscope 2014;124:1481-1485.

-2 Kay M, Wyllie R: Pediatric foreign bodies and their management. Curr Gastroenterol Rep 2005;7:212218.

-3 George AT, Motiwale S: Magnet ingestion in children - a potentially sticky issue? Lancet 2012;379:2341-2342.

4 Liu S, Lei P, Lv Y, Yan X, Ma H, Wang S: Diagnosis and treatment of magnetic foreign bodies in the digestive tract. Chinese Journal of General Surgery 2011;6:526-527.

5 Chen L, Hu B, Wang C, Tang C: Clinical analysis of 227 cases of foreign bodies in the upper gastrointestinal tract treated with endoscopic therapy. Chinese Journal of Digestive Endoscopy 2011;28:37-39.

6 Oestreieh AE: Worldwide survey of damage from swallowing multiple magnets. Pediatr Radiol 2009;39:142-147.

7 Smith MT, Wong RK: Foreign bodies. Gastrointest Endosc Clin N Am 2007;17:361-382.

8 Chung JH, Kim JS, Song YT: Small bowel complication caused by magnetic foreign body ingestion of children: two case reports. Pediatr Surg 2003;38:1545-155.

9 Liu S, Lei P, Fan C, Lv Y, Yan X, Wang S: Analysis of the geographical and social environment factors of the digestive tract injury caused by magnetic foreign body. Foreign Medical Geography 2011;32:95-97. 

www.karger.com/crg

Si et al.: Multiple Magnetic Foreign Bodies Causing Severe Digestive Tract Injuries in a Child

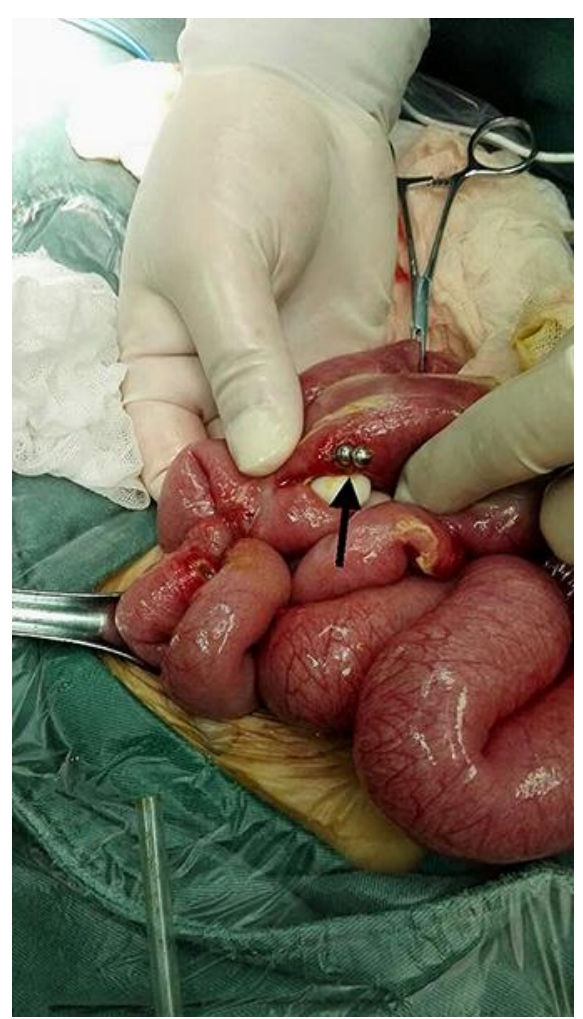

Fig. 1. Ankylenteron caused by magnetic attraction observed during surgical exploration (arrow). 


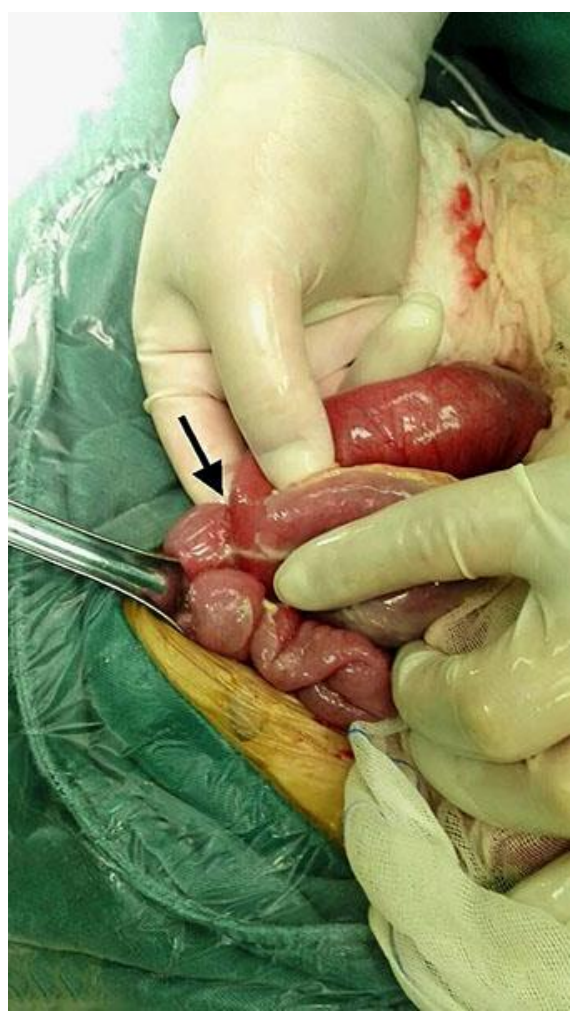

Fig. 2. Magnetic little balls inside the intestine observed during surgical exploration (arrow).

Si et al.: Multiple Magnetic Foreign Bodies Causing Severe Digestive Tract Injuries in a Child www.karger.com/crg 


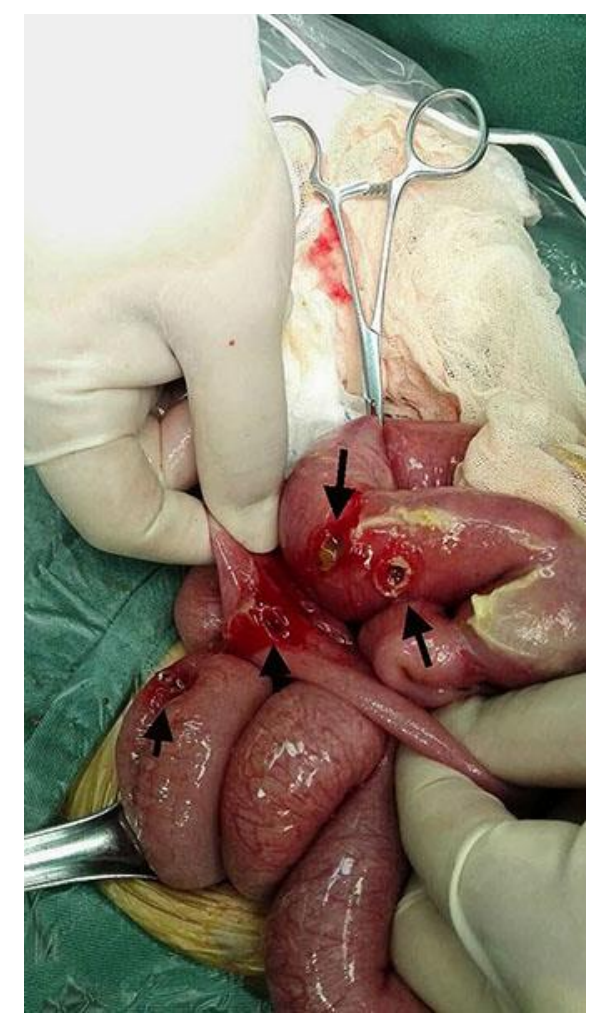

Fig. 3. Multiple intestinal perforations caused by magnetic attraction observed during surgical exploration (arrows). 


\begin{tabular}{ll|l} 
Case Reports in & \begin{tabular}{l} 
Case Rep Gastroenterol 2016;10:720-727 \\
\cline { 2 - 3 } Gastroenterology
\end{tabular} & $\begin{array}{l}\text { o } 2016 \text { The Author(s). Published by S. Karger AG, Basel } \\
\text { www.karger.com/crg }\end{array}$ \\
\cline { 2 - 3 } & $\begin{array}{l}\text { Si et al.: Multiple Magnetic Foreign Bodies Causing Severe Digestive Tract Injuries in a } \\
\text { Child }\end{array}$
\end{tabular}

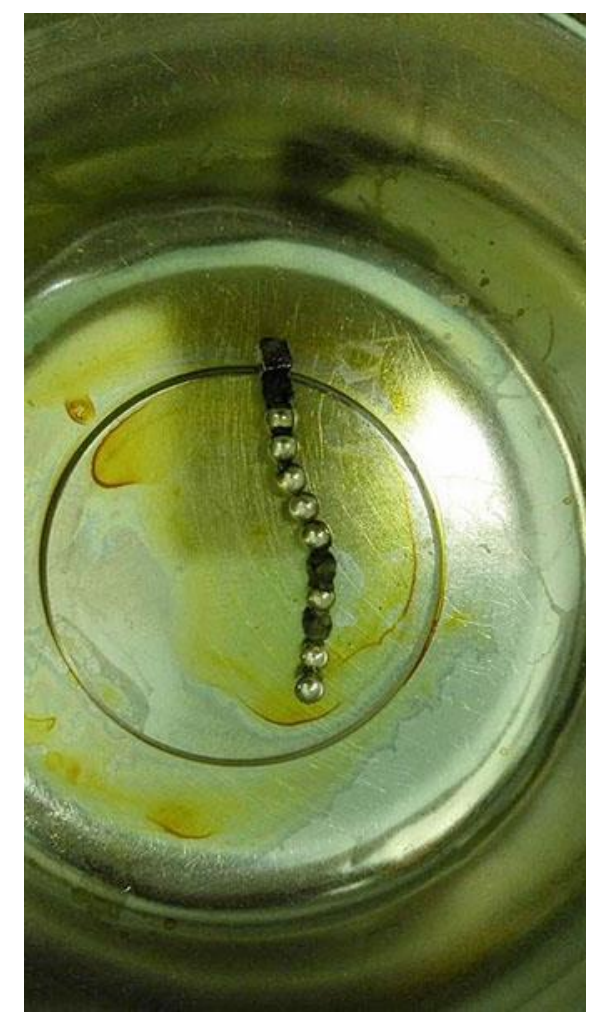

Fig. 4. Magnetic toys collected after removal. 